\title{
Esplenectomía laparoscópica por quiste hidatídico primario de bazo
}

\author{
Fernando L. Begliardo ${ }^{1}$, Milagros Corpacci ${ }^{1}$, Ramiro H. Gil ${ }^{1}$ y Fernando Martínez-Lascano ${ }^{1}$
}

\section{Laparoscopic splenectomy by primary hydatid cyst of the spleen}

Objective: Describe a case report of a hydatid splenic cyst of one year of evolution, treated by laparoscopy. Materials and Methods: A 36-year-old woman with left upper quadrant pain for 1 year. The topographic study showed a $67 \mathrm{~mm}$ splenic cystic lesion. Laparoscopic splenectomy was performed without incident. Result: Favorable post-operative evolution. Histology compatible with splenic hydatidosis. Discussion: The incidence of splenic hydatidosis is low, even in endemic areas, approaching $1-2 \%$. Surgery is the therapeutic strategy of choice, given the risks of rupture. However, there is no consensus regarding the technique. Conclusion: Laparoscopic splenectomy is a safe procedure supported by the literature.

Key words: hydatidosis; spleen; splenectomy.

\section{Resumen}

Objetivo: Describir el caso clínico de un paciente con quiste esplénico hidatídico de un año de evolución resuelto por vía laparoscópica. Materiales y Métodos: Mujer de 36 años con dolor en hipocondrio izquierdo por 1 año de evolución. El estudio topográfico objetivó lesión esplénica quística de $67 \mathrm{~mm}$. Se realizó esplenectomía laparoscópica sin incidentes. Resultado: Evolución posoperatoria favorable. Histología compatible con hidatidosis esplénica. Discusión: La incidencia de hidatidosis esplénica es baja, incluso en áreas endémicas, aproximándose al 1-2\%. La cirugía es la estrategia terapéutica de elección dado los riesgos de ruptura, sin embargo, no hay consenso respecto a la técnica de elección. Conclusión: La esplenectomía laparoscópica es una herramienta segura y avalada en la literatura.

Palabras clave: hidatidosis; bazo; esplenectomía.

\section{Introducción}

La hidatidosis humana es una zoonosis adquirida en forma accidental, causada por la forma quística de la larva del Echinococcus granulosus ${ }^{1}$. Constituye un problema de salud en distintas regiones del mundo, sobre todo en América del Sur (Argentina, Uruguay, Chile, Brasil y Perú), Australia y Nueva Zelanda, Asia, norte de África y sur de Europa. Actualmente, en nuestro país presenta una prevalencia del 1,5 por cada 100.000 habitantes al año ${ }^{2}$.

Esta parasitosis ha sido descripta en la mayoría de los órganos o tejidos del cuerpo humano. Entre el 50 a $60 \%$ de los quistes hidatídicos se sitúan en el hígado, seguido por los pulmones en un menor porcentaje (20 a $35 \%)$, mientras que el resto de los órganos son menos afectados ${ }^{2}$. La incidencia de esta enfermedad en el bazo es considerada baja, incluso en zonas endémicas, reportándose valores entre $1-3 \%{ }^{3}$.
La cirugía es el tratamiento indicado en la hidatidosis esplénica por el riesgo de rotura u otras complicaciones. No obstante, no existe consenso sobre la técnica quirúrgica de elección. Algunos cirujanos prefieren la esplenectomía total, y otros, procedimientos con preservación del bazo ${ }^{4}$.

En este reporte, describimos un caso de enfermedad hidatídica localizada solamente en el bazo, que acudió a nuestro hospital y en quien se optó por realizar la esplenectomía total por vía laparoscópica.

\section{Caso clinico}

Se presenta el caso de una mujer de 36 años de edad, oriunda de la localidad de Córdoba, República Argentina. Ingresó en por presentar por dolor abdominal localizado en hipocondrio y flanco izquierdo, acompañado de nauseas de 1 año de evolución. Al
'Servicio de Cirugía General, Nuevo Hospital San Roque, Córdoba, República Argentina.

Recibido el 4 de julio y aceptado para publicación el 12 de septiembre de 2018.

Correspondencia a: Dr. Fernando Luis Begliardo ferbegliardo@hotmail.com 


\section{CASO CLÍNICO}

Figura 1. Tomografía computada: imagen quística esplénica de $67 \times 62$ $\mathrm{mm}$ con paredes cálcicas discontinuas.

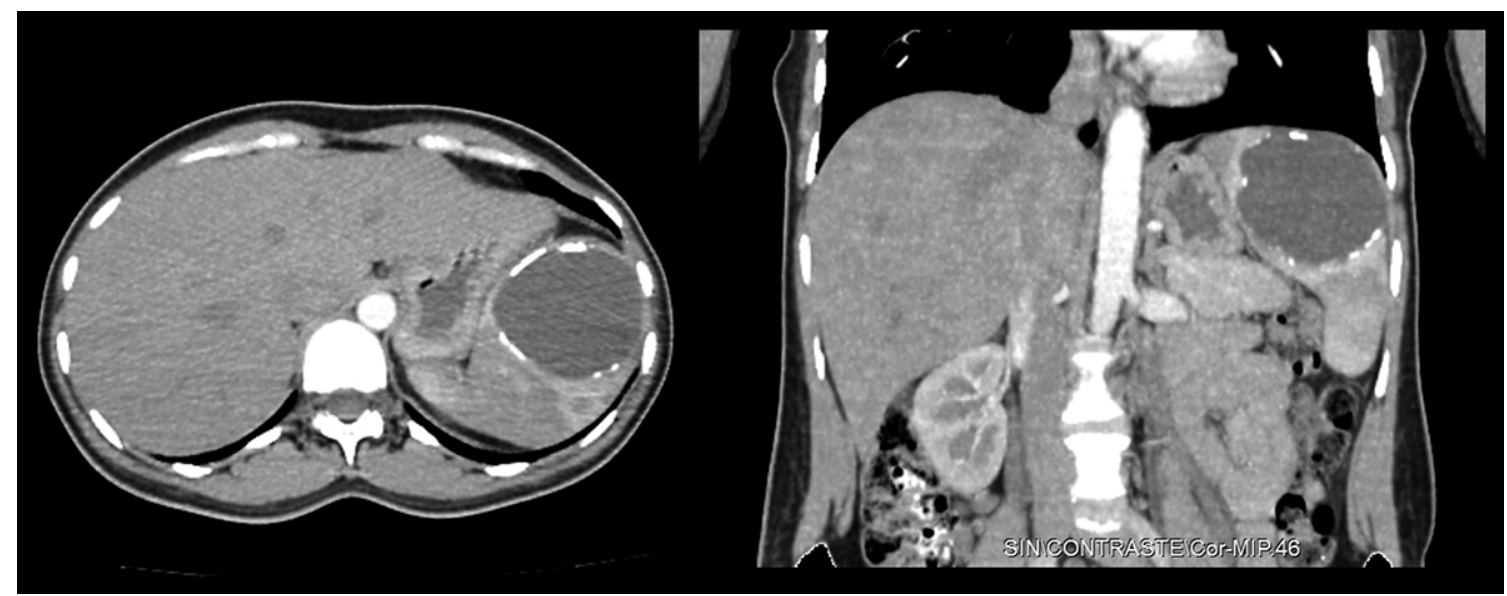

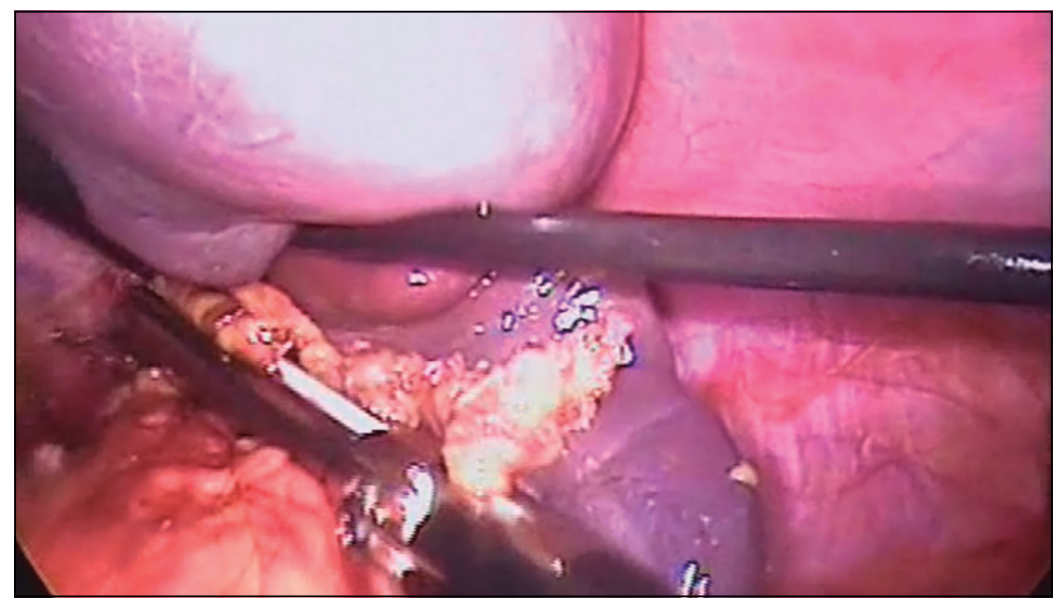

Figura 2. Ligadura de pedículo esplénico con sutura cortante laparoscópica.

examen físico, se palpaba una masa abdominal no dolorosa en el cuadrante superior izquierdo.

El laboratorio de rutina y las radiografías de tórax y abdomen se encontraban dentro de los parámetros normales. La tomografía computada informaba una imagen quística esplénica de 67 × $62 \mathrm{~mm}$, en polo superior, con paredes cálcicas discontinuas (Figura 1). El test de inhibición de la hemoaglutinación (IHA) para hidatidosis resultó negativo. Se comenzó tratamiento con albendazol $600 \mathrm{mg} /$ día por 30 días y luego se programó la esplenectomía laparoscópica.

En la sala de operaciones, bajo anestesia general, se ubicó a la paciente en posición de decúbito lateral derecho, con quiebra lumbar. Se colocó un trocar de $10 \mathrm{~mm}$ en región subcostal izquierda en línea medioclavicular, previa realización de neumoperitoneo con aguja de Veress, por el cual se introdujo una óptica de laparoscopía de $30^{\circ}$. Bajo visión directa se insertó un segundo trocar de $5 \mathrm{~mm}$ en epigastrio y otro de $12 \mathrm{~mm}$ en flanco izquierdo a la altura de la línea axilar anterior. Durante la semiología intraoperatoria se visualizó el bazo aumentado de tamaño con la lesión quística en polo superior. Se realizó la liberación del bazo mediante sección de los vasos cortos con Ligasure, liberación del ligamento espleno-cólico y de la cara izquierda del bazo. Se identificó el pedículo esplénico con maniobras romas. Se realizó ligadura del mismo mediante un disparo de sutura lineal cortante blanca de $60 \mathrm{~mm}$ (Figura 2). Se completó la liberación del órgano de todos sus restantes elementos de fijación. Se colocó la pieza operatoria en una bolsa y se extrajo a través de una incisión de Pfanennsteel. La duración de la cirugía fue de $98 \mathrm{~min}$.

Se otorgó el alta hospitalaria al tercer día postquirúrgico, con indicación de continuar con tratamiento antiparasitario por 2 meses más, y vacunación para neumococo, meningococo y hemophilus infuenza.

$\mathrm{Su}$ seguimiento fue por 18 meses sin presentar complicaciones ni recurrencias. La pieza de esplenectomía (Figura 3) midió $12 \times 8 \times 6,5 \mathrm{~cm}$, pesó 220 g. Al corte presentaba un quiste unilocular de 7 x 6 x $5 \mathrm{~cm}$, con capa blanquecina, en sectores calcificado y de contenido acuoso. El informe final fue de hidatidosis esplénica (Figura 4).

\section{Discusión}

Los quistes hidatídicos esplénicos tienen un crecimiento lento. En la mayoría de los pacientes, permanecen asintomáticos, y la detección de la enfermedad es incidental. Cuando el quiste alcanza un tamaño considerable, los pacientes pueden referir dolor inespecífico en el hipocondrio izquierdo (25- 
$35 \%$ ), siendo la esplenomegalia o masa palpable menos frecuente ${ }^{3}$. En casos desafortunados, los síntomas aparecen luego de alguna complicación como ser la infección, la hemorragia intraquístca, una fístula o la rotura espontánea o postraumática, con su consecuente shock anafiláctico ${ }^{5}$.

El diagnóstico está basado en el antecedente clínico, el examen físico, los métodos de imágenes y, en algunos casos, apoyado por la serología positiva ${ }^{4}$. La ecografía y la tomografía computada de abdomen son ambos métodos sensibles para detectar la hidatidosis. Las posibles imágenes que se pueden encontrar dependen del estadío del desarrollo quístico. La TC provee detalles estructurales adicionales; muestra la localización precisa del quiste y su profundi$\mathrm{dad}^{1}$. El test inhibición de la hemoaglutinación para hidatidosis, con una especificidad del 90-100\% y una sensibilidad del $68,4 \%$, puede arrojar resultados negativos si el quiste no tiene fugas o no contiene escólices, o el parásito ya no es viable ${ }^{1}$.

Según la guía para el equipo de salud del Ministerio de Salud de la República Argentina ${ }^{6}$, el albendazol está indicado en pacientes asintomáticos, como profilaxis prequirúrgica o en pacientes sintomáticos (no complicados) que tienen contraindicaciones para una cirugía. Los quistes más pequeños y con paredes finas, así como los que se presentan en los pacientes más jóvenes tendrían mejor respuesta al tratamiento farmacológico. Se indica antes de la cirugía programada a razón de $10-15 \mathrm{mg} / \mathrm{kg} / \mathrm{día}$ durante los 30 días previos y durante los 60 días posteriores a la misma.

No existe consenso con respecto a la selección del procedimiento quirúrgico, y la mayoría de los reportes han sido reportes de casos o series de bajo número de casos. La mayoría de los cirujanos recomiendan la esplenectomía total debido a la baja tasa de recurrencia ${ }^{4}$. Sin embargo, la tasa de mortalidad por sepsis es del 4\% para niños y $1,9 \%$ en adultos ${ }^{4}$. Por esta razón el número de cirujanos en favor de la cirugía con preservación de bazo ha aumentado. Este tipo de procedimientos incluye la esplenectomía parcial, enucleación, el destechamiento más omentoplastía o el drenaje externo o interno con cistoyeyunoanastomosis ${ }^{7}$. No obstante, presentan algunas complicaciones como ser la recurrencia y la formación de una cavidad residual.

Arikanoglu $\mathrm{Z}^{4}$ en una serie de 10 casos donde analizan los resultados y la efectividad del tratamiento quirúrgico y comparan la esplenectomía total con la cirugía de preservación de bazo, concluyen que la esplenectomía es preferida en la mayoría de los casos debido a la baja tasa de complicaciones, particularmente en aquellos quistes grandes

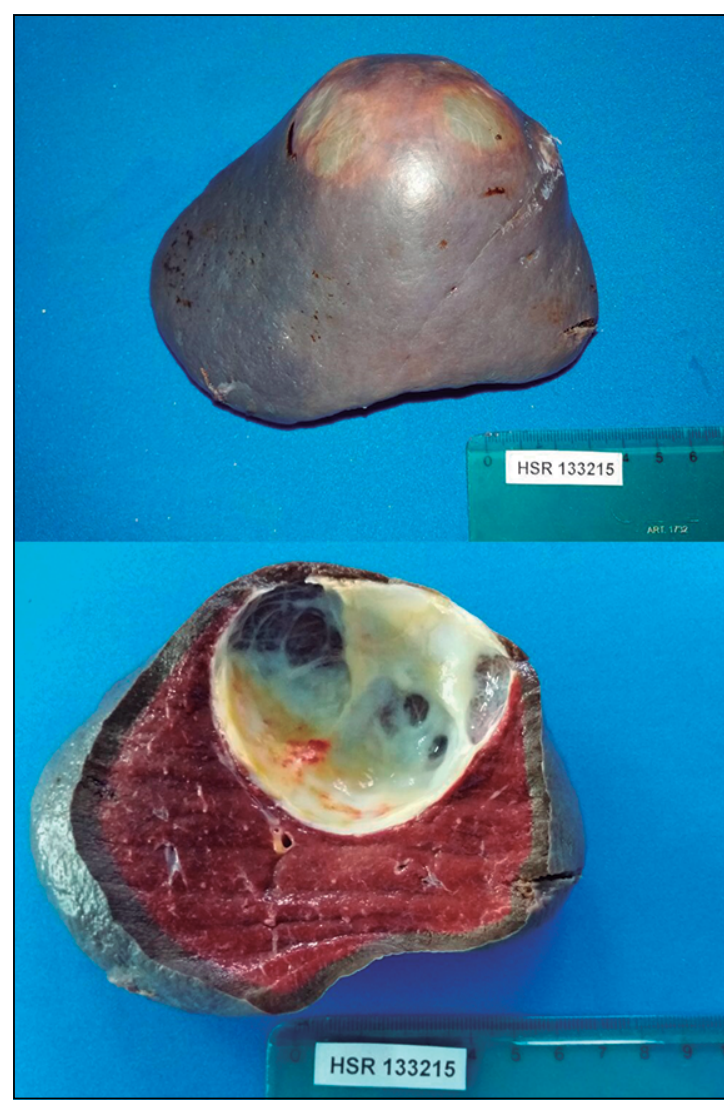

Figura 3. Pieza de esplenectomía de $12 \times 8 \times$ $6,5 \mathrm{~cm}, 220 \mathrm{~g}$, con quiste unilocular de $7 \times 6 \times 5 \mathrm{~cm}$.

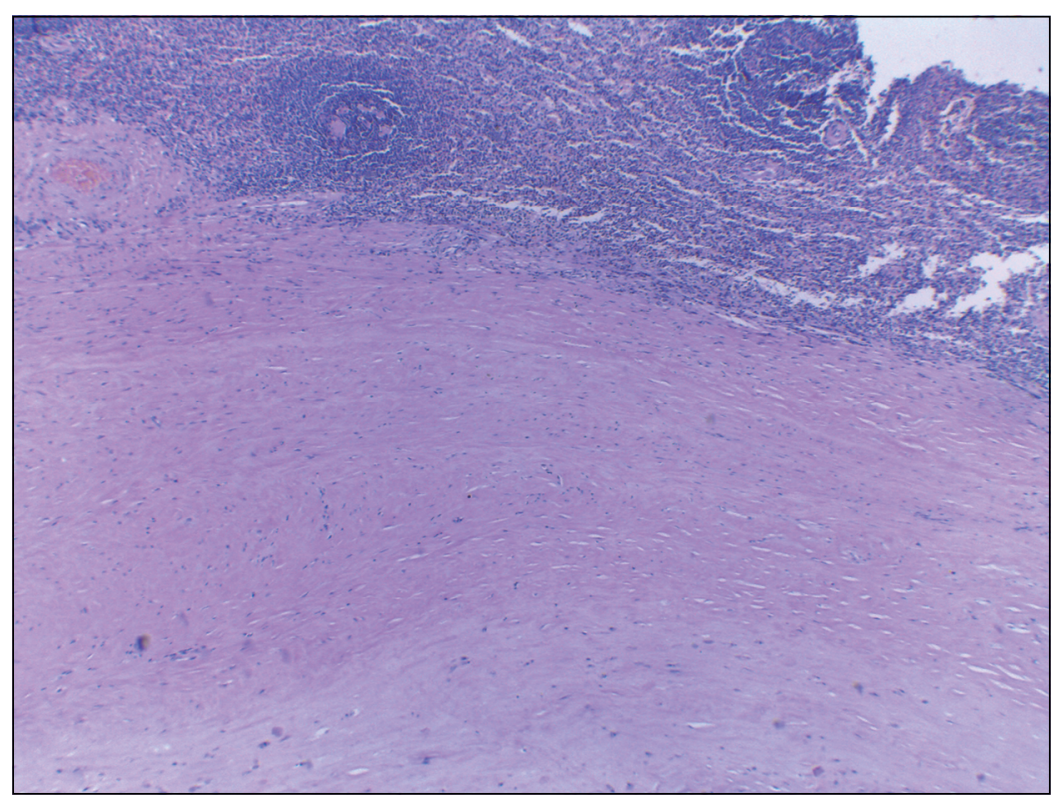

Figura 4. Examen microscópico donde se observa la pared del quiste hidatídico. Tinción hematoxilina-eosina $10 x$ 
o de localización central, reservando los demás procedimientos para quistes de pequeño tamaño y de localización periférica. Meimarakis $\mathrm{G}^{8}$ en una serie de 10 casos consideran que el procedimiento de elección es la esplenectomía ya que ofrece la cura completa de la enfermedad con tasas bajas de morbimortalidad.

En la era moderna, la cirugía laparoscópica se ha convertido en la elección para el manejo operatorio de las diversas lesiones esplénicas. Cuando se compara con la cirugía a cielo abierto, la laparoscopía provee mejor exposición intraabdominal, menor estadía hospitalaria, menor dolor posquirúrgico y mejores resultados cosméticos ${ }^{9,10}$.

\section{Responsabilidades éticas}

Protección de personas y animales. Los autores declaran que para esta investigación no se han realizado experimentos en seres humanos ni en animales.

Confidencialidad de los datos. Los autores declaran que en este artículo no aparecen datos de pacientes.

Derecho a la privacidad y consentimiento informado. Los autores declaran que en este artículo no aparecen datos de pacientes.

Conflictos de interés: Los autores no declaran conflicto de intereses.

\section{Referencias}

1. Nooghabi AJ, Raoufian K, Motie MR. Concomitant Splenic and Hepatic Hydatidosis: Report of Two Cases and Review of the Literature. Acta Médica Iránica 2015;53:74-7.

2. Giménez M. Cirugía. Fundamentos para la práctica clínico-quirúrgica. 1st ed. Buenos Aires: Médica Panamericana 2014:367-8.

3. Ferraína P, Oría A. Cirugía de Michans. 5th ed. Buenos Aires: El Ateneo 2002:703-4.

4. Arikanoglu Z, Taskesen F, Gumus H, Onder A, Aliosmanoglu I, Gul M, et al.
Selecting a surgical modality to treat a splenic hydatid cyst: total splenectomy or spleen-saving surgery? J Gastrointest Surg. 2012;16:1189-93.

5. Polat FR, Sezer A, Polat S. Laparoscopic treatment of hydatid cyst of the spleen without splenectomy: report of a case. Surg Laparosc Endosc Percutan Tech. 2009;19:215-6.

6. Ministerio de salud. Presidencia de la Nación. Enfermedades infecciosas, Hidatidosis, Guía para el equipo de salud 2012:20-1.

7. Atmatzidis K, Papaziogas B, Mirelis C, Pavlidis T, Papaziogas T. Splenectomy versus spleen-preserving surgery for splenic echinococcosis. Dig Surg. 2003;20:527-31.

8. Meimarakis G, Grigolia G, Loehe, Jauch KW, Schauer RJ. Surgical management of splenic echinococcal disease. Eur J Med Res. 2009;14:165-70.

9. Tagaya N, Oda N, Furihata M, Nemoto T, Suzuki N, Kubota K. Experience with laparoscopic management of solitary symptomatic splenic cysts. Surg Laparosc Endosc Percutan Tech. 2002;12:279-282.

10. Khoury G, Abiad F, Geagea T, Nabout G, Jabbour S. Laparoscopic treatment of hydatid cysts of the liver and spleen. Surg Endosc. 2000;14:243-5. 